\title{
A IMPORTÂNCIA DO DESENVOLVIMENTO INCLUSIVO EM CONHECIMENTOS SISTEMATIZADOS, POLÍTICOS, PESQUISAS E CONDUTAS NO GERIR DA GESTÃO E COORDENAÇÃO ESCOLAR
}

\author{
Sonia Alves dos Santos Silva ${ }^{1}$
}

RESUMO: O trabalho desenvolvido e apresentado a seguir nos leva em uma análise de políticas centradas no processo organizacional de uma gestão escolar. Um estudo baseado em referencias bibliográfico que apresenta concepções de teóricos como (LIBÂNEO, 2004; LUCK 199; CHAVIAVENATO 2000; TEIXEIRA E PORTO 1999. A análise teórica tem como objetivo a organização do espaço escolar o qual está inserido em aspectos políticos e sociais de forma democrática no processo de organização escolar e com ênfase na melhoria e qualidade de ensino com a interação da gestão e coordenação escolar em seus papéis mostrando a atuação destes profissionais através de competências desenvolvidas em suas praticas cotidianas em potencial de conhecimento individual e de equipe com embasamento sistematizado de forma cientifica e participativa no processo educacional e o reflexo na formação do educando que passa pelo ambiente escolar no decorrer da vivência escolar em desenvolvimento sistematizado para a formação humana que direciona a vida de forma inclusiva e ética.

Palavras-chave: Gestão escolar. Processo educacional. Organização.

\section{INTRODUÇÃO}

Este artigo foi elaborado a partir de leituras e estudos dos módulos acadêmicos disponibilizados pelo portal do aluno Faveni e com pesquisas teóricas referentes às temáticas das apostilas estudas no decorrer da formação. Com ênfase na participação democrática com o objetivo de motivar o processo organizacional com equipes gestoras motivadas para a articulação do desenvolvimento educacional de seus educandos e da organização do espaço escolar.

A escolha deste tema, para o presente Trabalho de Conclusão de Curso (TCC) iniciou com as reflexões obtidas no decorrer da formação nas aulas e explicações dos maravilhosos professores e vivências cientificas embasadas no conhecimento de cada

\footnotetext{
I Pós-graduação em Coordenação pedagógica e supervisão escolar. Com 720 horas. FAVENI. E-mail: prof.soniasurdez@hotmail.com.
} 
módulo estudado e ao adquirir de forma simultânea e reflexiva nos estudos acadêmicos e nas bibliografias disponibilizadas na grade curricular do mesmo. Sendo assim um ponto de partida para o desenvolvimento e análise do conhecimento adquirido para que sejam descritos e analisados neste para avaliação de nossa capacidade docente e eficaz para o âmbito educacional ao qual direcionamos nossos estudos para o desenvolvimento e aprendizagem do corpo organizacional que rege o ambiente escolar.

E ao se abordar a presente temática "Organização e gestão: fatores decisivos para uma escola de qualidade." E, tem como maior objetivo estudar a organização da equipe que direciona o espaço escolar, no caso, as lideranças, sendo os responsáveis para mediar um espaço de qualidade e significativo para o desenvolvimento, de forma acolhedora e eficaz.

Este artigo cientifico nos leva a entender que a formação continuada e em equipe auxilia na organização de uma equipe ao direcionarem seus anseios e necessidade do cotidiano objetiva a conhecer a realidade do dia a dia, bem como uma formação não mecânica e direcionada para a formação prazerosa, isso não vem a ser somente com crianças mas com os adultos da equipe também, de forma com que venham a se sentir importantes, o proporcionar dinâmicas de acolhidas de forma lúdica e eficaz, proporcionando a alegria do grupo de trabalho.

[...] A educação lúdica é uma ação inerente na criança e parece sempre como forma transacional em direção a algum conhecimento, que se define na elaboração constante do pensamento individual em permutações constantes com o pensamento coletivo [...] (ALMEIDA, 1995. P II)

Com tudo, toda atividade aplicada e desenvolvida no ambiente escolar precisa ser de forma eficaz e plausível para o desenvolvimento da equipe, uma equipe feliz proporciona um ambiente acolhedor e harmônico propicio ao desenvolvimento humano significativo. Sem discórdias ou intrigas, sendo que profissionais bem trabalhados emocionalmente, não tem tempo de reclamar, ou até mesmo denegrir os colegas. Dessa forma, pessoas bem resolvidas, não tem tempo a perder com coisas pequenas e que lhes causam danos a si mesmos.

Também é indispensável garantir o desenvolvimento e a imaginação, para permitir que aflore essa capacidade do ser humano, deve-se permitir que os momentos de atividade 
recreativa decorram de forma natural, espontânea, não excluindo a comunicação entre os pares no perímetro escola, sempre mantendo a cautela para não interferir de forma desnecessária para que não limite o desenvolvimento criativo, social e de equipe.

É importante que o Gestor valorize e perceba as maneiras constantes de desenvolvimento tecnológico e a forma com que isso intensifica de forma rápida e global, nesse contexto deve se identificar quais as culturas envolvidas no desenvolvimento escolar de sua equipe, de forma cautelosa, para não ferir a ninguém, sendo que cada um pensa de formas diferentes, dependendo das vivencias, inserções sociais, classe e cultura familiar.

Freire (2006, P.103) ressalta que, tão importante quanto o ensino dos conteúdos, é o testemunho ético ao ensiná-lo. É a decência com quem se faz. É a preparação científica revelada sem arrogância, pelo contrário, com humildade. Ainda de acordo como autor, (Freire2006, p.33) o caráter formativo implica no respeito á natureza do ser humano, e os conteúdos que são ensinados devem estar aliados a uma formação moral, pois enfatiza que ensinar é substantivamente formar e que essa formação é feita por construções do dia a dia e de momentos significativos para assimilar e se desenvolver, os sentimentos e afetos são favoráveis para a significante aprendizagem de valores educativos que permeiam a vida humana em sua aprendizagem cotidiana e na base que são as primeiras aprendizagens. Por isso os educadores devem ensinar e direcionar o desenvolvimento e aprendizagem no processo de formação grupal e sistematizada.

Por fim, sabe-se que haverá desafios futuros na área da educação para que os gestores e coordenadores tenham uma formação continua e eficaz no processo de comunicação, para assim direcionar as organizações e para as equipes estarem desenvolvidas de acordo com o conhecimento adquirido de forma rápida e tecnológica para e esta e próximas gerações que serão desafios com necessidades de se promover respostas adequadas para preencher as lacunas que são naturais, pois, com o decorrer dos anos, a as mudanças trazem a necessidade de se evoluir e de se adaptar sendo realmente algo a se pensar e a estudar para que os cooperadores não se percam nesse meio campo, que tenham muito cuidado na aquisição de conhecimento e que sejam pesquisadores e inovadores em suas didáticas se tornando profissionais apaixonados pela profissão e que façam a diferença na vida da equipe escolar e de toda a sociedade em um processo de construção e 
desenvolvimento humano e na aquisição comunicativa, formativa e profissional em todas as áreas envolvidas com aprendizagem significativa e valorização da cultura do meio envolvido, pois com os estudos da formação foi possível perceber que as equipes usam as estratégias do meio para se comunicarem e a se desenvolverem como pessoa em sua cultura pessoal e social e acima de tudo profissional. Não deixando de brilhar como os melhores que se tornarão ao aprenderem a serem pesquisadores e que vivenciem formações com experiências e vivencias do meio escolar para se portarem de forma ética, e sempre pesquisando as inovações no campo de atuação, pois o meio escolar modifica em sua cultura a todo o momento, lembrando que a forma de atuação dos profissionais do ambiente escolar se modifica a todo o momento de acordo com as novas regras, estudos e pesquisas, com atuações de didáticas lúdicas e de acordo com o desenvolvimento de cada criança e dos profissionais do espaço institucional e com atuações éticas e inclusivas.

\section{FUNDAMENTOS TEÓRICOS}

A expressão gestão escolar, vem substituindo o termo administração escolar, o que representa uma grande mudança de postura, uma nova organização com amparo a princípios de participação, de autonomia, de autocontrole e de responsabilidade. Dessa forma "A gestão não deprecias a administração, mas supera as suas limitações de enfoque dicotomizado, simplificado e reduzido, para atender as exigências de uma realidade cada vez mais ampla e dinâmica." ( LUCK, I998, p.II)

Ainda sobre a importância da manutenção e, de se proporcionar esse contato entre um ou vários grupos de pessoas é possível reafirmar que é por meio da comunicação e interações que são formados alguns processos culturais, sendo que, os sujeitos tendem a absorver alguns conhecimentos que foram construídos, formados ou desenvolvidos por seus antepassados, pelas gerações anteriores e assim por diante. E o gestor é muito importante nessa mediação de construção do conhecimento e desenvolvimento do grupo de trabalho em análise de sua gestão já traz de casa os primeiros índices e esse observar e mediar conhecimentos faz com que se desenvolva com segurança e a aprendizagem permaneça e evolua para as etapas seguintes do desenvolvimento no espaço escolar. 
A partir disso, por isso, pode-se afirmar que a socialização e o dialogo são elementos indissociáveis ao meio escolar, pois incide diretamente na transformação de cada um, somado a isso ao desenvolvimento humano por um todo, o vigia, as nutricionistas, equipe de limpeza e a equipe que faz a mediação sistêmica do processo de aprendizagem significativa do meio cultural. Observe:

$\mathrm{Na}$ construção das funções superiores (pensamento, linguagem, criatividade, imaginação), a brincadeira é muito importante de ser estudada, não só porque representa o primeiro momento na construção da imaginação, mas também porque dá origem a vários processos psicológicos fundamentais ao desenvolvimento da criança (VIEIRA; CARVALHO; MARTINS, 2005, p. 40).

E, nesse momento para aprendermos sobre os novos padrões de qualidade para os comportamentos mediados e adquiridos no meio de vivências escolares de, necessariamente, qualidade pautadas nos valores e, abordar as pratica individualistas tão arraigadas no nosso cotidiano escolar para construir alternativas pensadas tão arraigadas no nosso cotidiano escolar e a partir á família e perpassa pelo criativo da responsabilidade, da sensibilidade, da implantação de mudanças do comprometimento como pressupõe um novo enfoque de gestão, o que leva o caminho para uma escola de qualidade pautada nos valores inerentes voltarmos a referir às primeiras expressões do contexto de gestão democrática e eficaz. Assim começam a conhecer espaço escolar de forma mais real, além de novas aprendizagens, a curta bagagem que possuem passa por uma redefinição devido à relação com o outro ser, com a equipe educacional e com aspectos em das partes distintas, seja social, religiosa, política ou cultural. O que ocorre na formação humana.

Podemos assim destacar o que afirma Vaz e Bezerra:

A escola funciona como um lugar essencialmente de comunicação e relação interpessoal, e é também o lugar da manifestação dos conflitos socioculturais. É nela que os alunos vivenciarão em primeira instância a luta entre o tradicional já instituído e a criação das muitas possibilidades de mudança. É nela também que o aluno testa o poder instituído na figura do professor $e$ as suas próprias possibilidades de exercer este poder. Há necessidade de aprimoramento com base teórica e pratica sobre gestão democrática para que a equipe escolar possa exercer com autonomia pedagógica e administrativa e de gestão financeira É inerente a escola, os conflitos relacionais, sejam eles de ordem do seu papel de interação interpessoal, sejam eles de ordem essencialmente politica. Aliado aos conflitos inerentes aos processos vividos pela escola percebe se o cenário atual mundial como um universo em crise de valores instituídos devido ao avanço da globalização. Assim, a família única, que transmite valores sociais imutáveis. A escola, principal parceria da família até então, encontra se em conflito sobre o seu papel social, já 
que os modelos antigos têm se mostrado ineficientes para o enfrentamento desta nova realidade.

E, por essas e outras afirmativas, nota-se que tais atividades relacionadas anteriormente, frente ao exposto percebem que a solução de tais conflitos pode estar na coletividade, participação, habilidade e competência, como condições fundamentais para a democratização, melhoria, qualidade da Educação e a transformação da sociedade inserida, uma vez que, as relações sociais seguem constantemente por toda vida.

Por isso, existe a necessidade de que o gestor entenda que sua atuação vai além de gerir o espaço escolar, o ensino em seu significado é amplo e está ligado de maneira indissolúvel à formação de um ser humano, que fará parte de um complexo mecanismo de sobrevivência em coletividade, e que esse ser é peça fundamental para o futuro de uma sociedade que sem princípios, moral, ética, respeito, educação e empatia, caminhará para ser realmente seu próprio lobo. Além disso, destaca-se a importância educadora materializar o objeto de ensino, e também esclarecer, aplicar de forma simples e objetiva o que está presente nos planos de ação educacional de forma ampla e inclusiva que atenda a todos as pessoas envolvidas no ambiente escolar.

Por tanto, destaco uma ótica voltada à necessidade de se enxergar as práticas da adaptação com sua devida importância, pois é uma ferramenta bastante positiva não deixando dúvidas sobre sua eficiência, devidas também sua completude cognitiva, moral e psicossocial com as culturas envolvidas e o desenvolvimento significativo dos profissionais no espaço escolar. Sendo nesse caso o gestor como mediador.

Assim, os meios utilizados pelos gestores no decorrer dos estudos observados, mostrou uma forma de desenvolvimento dos objetivos que foram planejados por meio de um segmento já pré-estabelecido em estudos dos módulos do portal acadêmico. Tornando assim a nossa aprendizagem bem produtiva e organizada. Por exemplo, uma forma de desenvolvimento e adaptação de estudo e pesquisas para o melhor desenvolvimento da equipe inserida no ambiente escolar, bem como os gestores e a organização da equipe nos espaços formativos e educacionais.

O modelo de gestão:

O jogo inclui características: simbolismo: representa a realidade e atitudes; significação: permite relacionar ou expressar experiências; atividade: a criança faz 
coisas; voluntario ou intrinsicamente motivado: incorporar motivos e interesses; regrado: sujeito e regras implícitas, e episódicas: metas desenvolvidas espontaneamente. (FROMBERG, 1987, p.36 apud KISHIMOTO, 1996, p. 27)

Dessa maneira, a aprendizagem através processo educacional planejado, organizado com pessoas capazes de criar e recriam o espaço vivencial, pelo gestor e permitem várias articulações que resultam no desenvolvimento Eficaz e, em decorrência disso, essa relação e método de ensinar e as interações dos funcionários As melhores escolas, melhores gestões são as que realmente buscam, cressem e se desenvolvem. Assim o melhor gestor vem se destacando e ganhando maior visibilidade, se tornando até um meio essencial de mediadores, uma vez que, a liderança comunicativa é um desenvolvimento significativo dos espaços escolares e familiares. Tornando primeiras formas de expressões de um comportamento, principalmente nos espaços escolares exato momento em que se ocorrem várias alterações em seu desenvolvimento e na sua capacidade interação e os estímulos coerentes e significativos para o desenvolvimento pleno das vivências e lideranças mediadas nos espaços educacionais de forma inclusiva com pesquisas e valorização.

\section{${ }_{4}$ CONSIDERAÇÕES FINAIS}

Em consequência do exposto, de todas as experiências estudadas, importante destacarem que o meio de vivência e profissional no gestar um grupo de trabalho em consonância com o dia a dia do ser humano o que precisa ser analisada para que os gestores sejam bem receptivos. E que a democratização do saber se dará em momentos que a sociedade seja conscientizadas o que consiste realmente o processo de organização e gestão, para, tanto cabe a aos educadores e gestores, buscar conhecimento teórico-metodológicos e consensuais que permitam a promoção de uma efetiva gestão democrática, onde as relações de poder possam ser repensadas de modo que a efetiva participação de todos os atores sociais e comunidade escolar sejam constantes e ocorra de forma critica e reflexiva, ressaltando se nesta ótica a importância do desenvolvimento deste estudo.

Acredita-se que somente uma educação de qualidade poderá levar à mudança social. Pessoas que sabem ler e escrever, sempre atuantes em pesquisas questiona e exige que não aceitem imposições ou manipulações, poderão contribuir para instaurar uma nova estrutura 
social, não de domínio, mas de respeito, inclusivo e de reconhecimento, não de opressão, mas de diálogo, em que as diferenças econômicas e sociais que não seja tão dispares.

Embora o estudo tenha sido bastante sistematizado e de forma individual no portal do aluno, evidenciaram-se os fatores que permeiam este processo. Assim, entende-se que os objetivos propostos neste artigo foram alcançados, bem como sua hipótese claramente confirmada, pois a organização e gestão escolar quando acontece de maneira participativa representa a interação entre os diversos segmentos da comunidade escolar visando o melhor aprendizado e a formação de cidadãos conscientes de seus deveres e direitos.

O presente artigo poderá ser útil as pessoas ligadas a educação, seja para fundamentar futuras pesquisas ou para fomentar ações gestoras, pois demonstra de forma clara e objetiva que é fundamental proporcionar espaços para o diálogo e a reflexão constante na busca pela gestão de qualidade e eficaz no desenvolvimento pessoal, escolar inclusivo e social.

\section{REFERÊNCIAS BIBLIOGRÁFICAS}

ALMEIDA, Paulo Nunes De. Educação Lúdica: Técnicas E Jogos Pedagógicos. São Paulo: Loyola, I995.

BRASIL. Ministério Da Educação. Lei De Diretrizes E Bases Da Educação Nacional. Lei № 9.394 De Dezembro De 1996. Estabelece As Diretrizes E Bases Da Educação Nacional. Disponível em: Http://Portal.Mec.Gov.Br/Seesp/Arquivo/Pdf/Lei9394. Acesso em in de junho de 202I.

CHIAVENATO, I. Introdução à teoria geral da administração. 6. Ed. Rio de Janeiro: Campus, 2000.

FERRARI, A. T. Metodologia da Ciência. 2. ED. Rio de janeiro: Kennedy, 1974.

FREITAS, Maria Ester de. Cultura Organizacional: Identidade, sedução e carisma? Rio de Janeiro, Editora FGV, 2000.

FRIGOTTO, Gaudêncio. Qualidade E Quantidade Da Educação Básica No Brasil: Concepções E Materialidade. Rio de Janeiro, 2012.

FREIRE, Paulo. Pedagogia Do Oprimido. Rio de Janeiro: Paz e Terra, 2014.

FREIRE, Paulo. Pedagogia da autonomia. Rio de Janeiro: Paz e Terra, 2006. 
GADOTTI, M.; Romão, J. E. Autonomia da escola: princípios e propostas. 2. Ed. São Paulo: Cortez, 1997.

LIBÂNEO, José Carlos. Organização e gestão da escola: teoria e prática. 5. Ed. Revista e ampliada. Goiânia: Editora Alternativa, 2004.

LEONTIEV, Alexis N. Uma contribuição à teoria do desenvolvimento da psique infantil. In. Vygotsky, Lev S. (et al.). Linguagem, desenvolvimento e aprendizagem. 6.ed. São Paulo: Ícone, 200Ib. p. 59-83.

Secretaria de educação especial. O tradutor e interprete de língua brasileira de sinais e língua. Programa Nacional de Apoio à educação de surdos - Brasília: MEC; SEESP, 2004.

LUCK, Heloísa. A evolução da gestão educacional, a partir da mudança paradigmática. Petrópolis: Vozes, 1998.

MARCONI, M. de A.; LAKATOS, E.M, Metodologia de pesquisas. São Paulo: Atlas, 200 .

O Interprete de Língua de Sinais no contexto de uma aula de alunos ouvintes. In: LACERDA, C. B. F. de. Góis, M. C. R. de (org.) SURDEZ: processos educativos e subjetividade. São Paulo: LOVISE, 2000.

PARO, Victor Henrique. Gestão Democrática da Escola Pública. São Paulo: Ática, 1997.

QUADROS, R.M. de ( 1996 ) - A aquisição/aprendizagem da Língua Portuguesa (L2): O contexto da pessoa surda. Porto Alegre: PUCRS.

SOUZA, Eulina Castro de. A importância do lúdico na aprendizagem. 2015. Disponível em: http://www.seduc.mt.gov.br/Paginas/A-import\% $\mathrm{C}_{3} \% \mathrm{~A} 2$ ncia-do- $1 \% \mathrm{C}_{3} \%$ Acesso em II de junho de 202I.

TEIXEIRA, Maria Cecilia Sanches; PORTO, Maria do Rosário Silveira. Gestão da escola: Novas perspectivas. São Paulo: Apostila, 1999.

VALERIEN, Jean. Gestão da escola fundamental: subsídio para análise e sugestões de aperfeiçoamento. (José Augusto Dias, tradução e adaptação): 4. Ed. São Paulo: Cortez; Paris; UNESCO; Brasília, Ministério da Educação e Cultura, 1993.

VAZ, Márcia Araújo; BEZERRA, Maria do Socorro Félix. Gestão escolar e o sucesso pedagógico na escola municipal Aurélio Buarque de Holanda. Moodle3.mec.gov.br/.../TCC_Maria_do_socorro_e_Maria_Vaz_ok.doc. Acessado em 17 de junho 2021. 
VIEIRA, Therezinha; CARVALHO, Alysson; MARTINS, Elizabeth. Concepções do brincar na psicologia. In. CARVALHO, Alysson et.al. Brincar(es). Belo Horizonte: Editora UFMG, 2005. p. 29-50.

VIOLADA, Rosiane. Brincadeiras e jogos na educação infantil. 2014.

KISHIMOTO, Tizuco Morchida. Jogo, brinquedo, brincadeira e a educação. 7. ed. São Paulo: Cortez, 1996. 